\title{
MODELING OF THE REINFORCEMENT POLARIZATION RANGE IN CORROSION TESTS
}

\author{
Tomasz JAŚNIOK* \\ Silesian University of Technology, Akademicka 5, 44-100 Gliwice, Poland
}

Received 11 January 2019; accepted 1 July 2019

\begin{abstract}
This paper presents the results of modeling of the potential distribution in DC corrosion tests with the application of the ANSYS Maxwell software in two models: in the form of a single long bar covered with concrete and in the shape of a fragment of the bar cut out together with the core. Material parameters used for input in the ANSYS Maxwell software were adopted from tests performed in aqueous solutions. The results of the simulation led to the conclusion that the corrosion tests on the cores cut out from the structure are universal so that regardless of the concrete conductivity and the advancement of steel corrosion processes they produce correct values of the corrosion rate. Meanwhile, the measurements taken within the structure will always require some measures to limit the range of polarization or allow its estimation.
\end{abstract}

Keywords: reinforced concrete structures, reinforcing steel, polarization resistance method, electrochemical impedance spectroscopy, finite element method, modeling of potential distribution.

\section{Introduction}

Expectations of high reliability and the need to ensure good technical conditions of the existing facilities is the driving force of the continual development of the research methods and the search for solutions enabling reliable diagnostics of corrosion risk of the reinforced concrete structures. The current standard solution is the use of polarization methods in the reinforcement corrosion tests: measurement of linear polarization resistance (LPR), galvanostatic pulse (GP) technique and electrochemical impedance spectroscopy (EIS). In all the above mentioned methods the measurements are carried out within the so-called three-electrode system, in which the working electrode is a rebar and the counter electrode together with the reference electrode (with constant and familiar potential) are applied to the concrete surface.

Regardless of the method used, the most difficult measurement problem is the lack of knowledge on the tested surface of the reinforcing bars necessary to determine the reinforcement corrosion rate. The range of the impact of the currents depends mainly on the advancement of the corrosion processes at the surface of steel as well as on the conductivity of the concrete (Andrade \& Alonso, 1996, 2001). The lack of action aimed at limiting or assessing the polarized reinforcement surface can result in "gross" mistakes while determining the current corrosion rate.
This article presents the results of ANSYS Maxwell modeling of potential distribution in DC polarization studies of reinforcement in aqueous solutions in which no measures restricting the distribution of polarization currents were implemented and where the polarization range was limited by means of an insulator around the counter electrode. Moreover, the results of the modeling of potential distribution in the core cut out from the structure according to patent (Zybura, M. Jaśniok, \& T. Jaśniok, 2012) are presented in which the rebar section is polarized with a counter electrode along its entire length. The modeling was carried out in two different environments causing different corrosive activity.

\section{The range of the potential distribution modeling}

Two types of environmental conditions have been adopted in the modeling of the potential distribution. In the first case, the modeling of concrete with extremely low protective properties with respect to steel in the presence of chlorides was performed, and the steel was at an advanced corrosion stage. In the second case, "sound" concrete was modeled ensuring good protective properties with respect to steel, and the steel was in a passive state.

${ }^{*}$ Corresponding author. E-mail: tomasz.jasniok@polsl.pl 
Modeling was performed with ANSYS Maxwell - a low-frequency electromagnetic field simulation software based on Maxwell's equations. It is used to design and analyse $2 \mathrm{D}$ and $3 \mathrm{D}$ electromagnetic, electromechanical and electric systems. The software uses the adaptive meshing techniques to generate the appropriate finite element mesh. ANSYS Maxwell performs a fully automated computation process that requires geometry input, material properties assignment and indication of the custom analysis results by the user.

The software library contains only the most popular materials with constant electrical parameters. Concrete is characterized by significantly variable electrical parameters depending on its moisture content, cement and additive type as well as chloride content. Likewise, steel in a highly alkaline environment such as concrete has completely different electrical properties on the surface and inside the cross-section. The results of the research presented in (Zybura et al., 2012) were used for the input of the appropriate material properties to the model. They were related to the potential distribution during the polarization tests on the length of the bar immersed in aqueous solutions carried out in the system shown in Figure 1.

This research describes tests carried out in solutions prepared on the basis of $\mathrm{C} 20 / 25$ class crushed concrete made of cement CEM I 42.5R sieved through a $0.2 \mathrm{~mm}$ mesh sieve. Then distilled water was added to the resulting powder with 1:1 weight ratio. For a period of about 48 hours the solution was stirred every 8 hours and after this the liquid was filtered off. Next, in the first case, carbon dioxide gas was passed through the liquid reducing the $\mathrm{pH}$ to 9.5 and $\mathrm{NaCl}$ was added to prepare a $3 \%$ concentration of $\mathrm{Cl}^{-}$by weight. The solution prepared in that way modeled a type of concrete which had extremely low protective properties with respect to steel in the presence of chlorides. The measured conductivity of the solution was $5.24 \mathrm{~S} / \mathrm{m}$. In the second case, the initial liquid was not modified, since it was an attempt to model "sound" concrete which would protect steel against corrosion. This solution was characterised by $\mathrm{pH}=12.4$ and $0.8 \mathrm{~S} / \mathrm{m}$ conductivity.

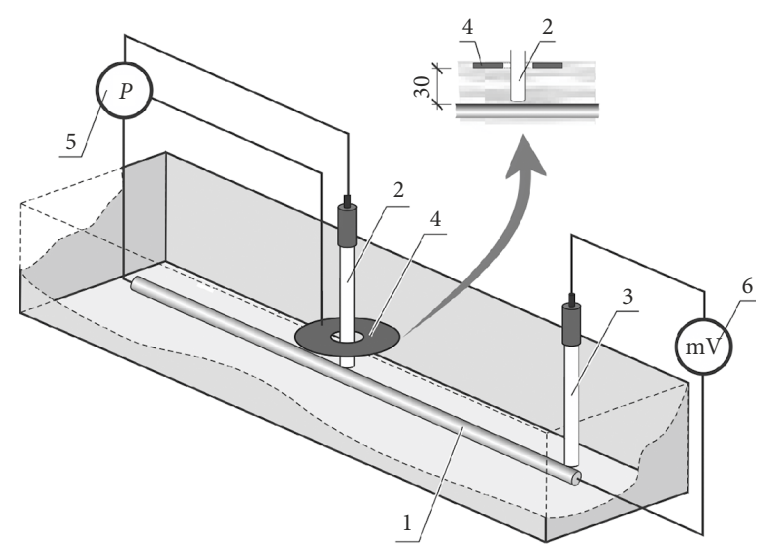

Figure 1. View of the measuring system used for the experimental determination of the electrical characteristics of the water solutions and the reinforcing bar according to

(M. Jaśniok \& T. Jaśniok, 2017) - description in the text
A mechanically polished $500 \mathrm{~mm}$ length reinforcing bar 1 of S235 steel and $10 \mathrm{~mm}$ in diameter was inserted into a vessel filled with one of the two solutions described above (Figure 1). The rebar acted as the working electrode. The first (silver chloride) reference electrode 2 was placed $2 \mathrm{~mm}$ above the centre of the bar surface while at the same distance from the steel surface at the end of the bar the second reference electrode 3 was fixed. The research involved the use of a circle-shaped counter electrode 4 with a $75 \mathrm{~mm}$ diameter made of stainless steel, which was placed above the centre of the rebar at a distance of $30 \mathrm{~mm}$ from its surface. The distance of $30 \mathrm{~mm}$ may correspond to the thickness of the concrete cover of the structure exposed to the aggressive effect of the environment. The 1 , 2 , and 4 electrodes were connected to the potentiostat 5 to form the classic three-electrode system. Meanwhile, the electrode 3 was connected to the milli-volt meter 6 enabling the availability of readings of the potential changes at the end of the rod. It was a control measurement used in the modeling of the potential distribution.

In order to simulate the corrosive conditions prevailing in both characteristic solutions the modeling took into account the fact that the measured conductivity of the solutions used in the research will be directly applied in the model with the value of the relative permittivity in the model taken to be equal to that of water $\varepsilon_{\mathrm{w}}=80.1$ (Figure $2 \mathrm{a}$ and $\mathrm{b}$ ). Whereas, while determining the electrical properties of corroded and passivated steel a specimen method was used. For this purpose, in the first approach the electrical properties of the carbon steel material of the bar (also of the stainless steel of the counter electrodes) were taken to be the same as for metallic conductors (conductivity $\sigma_{\mathrm{s}}=10^{8} \mathrm{~S} / \mathrm{m}$, relative electrical conductivity $\varepsilon_{\mathrm{s}}=1.0$ ). The system shown in Figure 1 was modeled in the software and the value of the potential was read at the point of application of the reference electrode 3 (Figure 1). Only in the case of the solution which modeled concrete with very low protective properties (Figure 2a) the potential identified in the model and measured in the tests was similar (the change in the potential was approximately equal to 0 ). Meanwhile, in the case of the solution that modeled "sound" concrete it was necessary to modify the material of the reinforcing bar, which involved introducing a layer (simulating the oxide layer) on its surface made of an unspecified material with a thickness of $t=1 \mathrm{~mm}$ (Figure $2 \mathrm{~b}$ ). The relative permittivity of the layer $\varepsilon_{\mathrm{p}}$ was arbitrarily taken to be equal to 1 , while the electrical conductivity $\sigma_{\mathrm{p}}$ was set at $1.0 \mathrm{~S} / \mathrm{m}$ where the reading of the model's potential at the end of the bar was equal to the one measured in the experimental study.

Since the tests (M. Jaśniok \& T. Jaśniok, 2017) involved a bar of a considerable length, the software modeling of the potential distribution was also performed lengthwise of the reinforcing bar for the system shown in Figure 1. The scheme of this model along with its dimensions can also be seen in Figure 2c. The measure taken to restrict the polarization currents was modeled as an incision of con- 


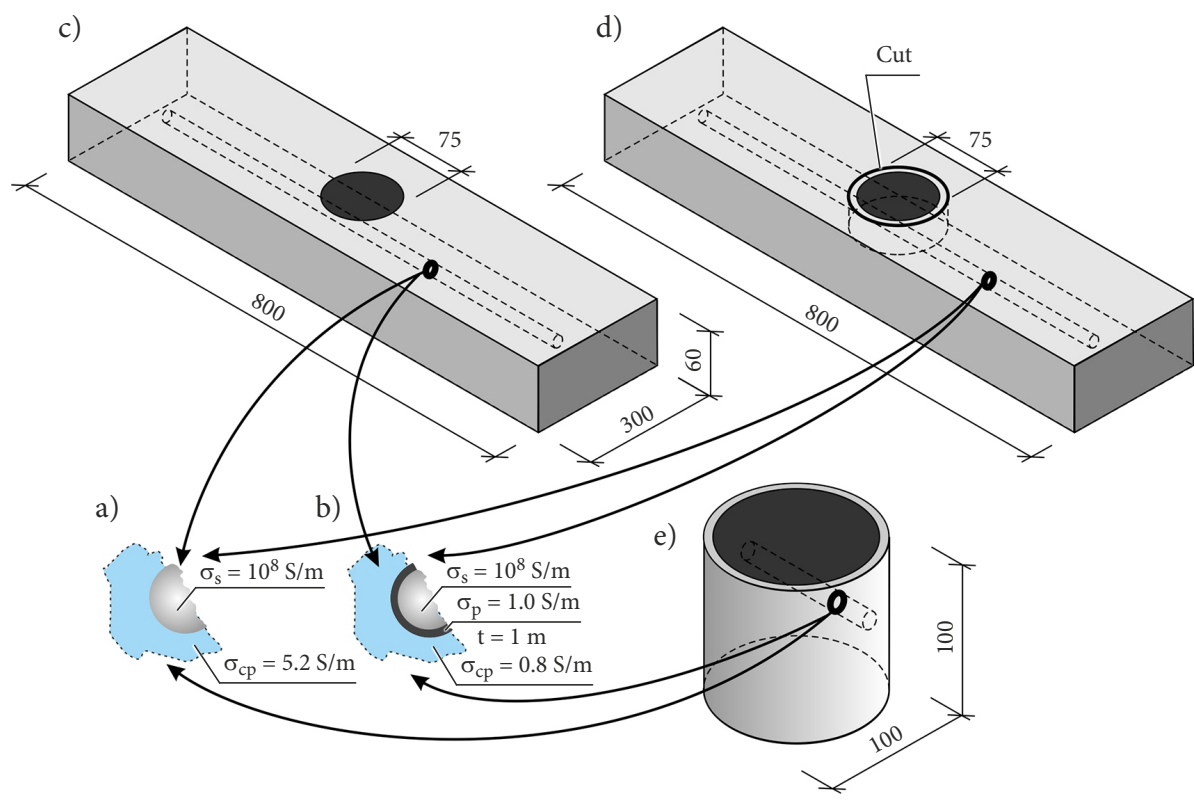

Figure 2. Research schemes and materials assumptions taken into account for modeling of potential distribution - description in the text

crete around the counter electrode (incision as an electrical insulator), the diagram of which is shown in Figure 2d. Figure $2 \mathrm{e}$ shows a concrete cylinder with a fragment of a bar which modeled the tests carried out on the cores cut out of the structure according to the patent (Zybura et al., 2012). In all of the above mentioned diagrams aqueous solutions approximating the concrete with very low protective properties with respect to steel as well as the "sound" concrete have been taken into account (Figure $2 a$ and $b$ ).

\section{The results of the potential distribution modeling}

The results of the potential distribution modeling in different research designs and various environmental conditions are presented in Figure 3.

Based on the results shown below it is noteworthy that the distribution of the potential to a large extent depends on the conductivity of the environment and on the advancement of the corrosion processes on the surface of the rod. In the case of strong advancement of corrosion processes the polarization range is insignificant, it is located near the counter electrode - see Figure 3a. Limiting the polarization range in this particular case by cutting the concrete around the counter electrode (introduction of the insulator) also limits the impact of the current to the area of the bar located directly under the counter electrode see Figure 3c.

Meanwhile, the low corrosion rate is a totally different case. The current flow between the counter electrode and the bar covers all its surface and at the end of the bar one can read the value of the potential of several millivolts see Figure 3b. The performed incision limits the range of the polarization current significantly, however, it does not limit it to the extent previously assumed or foreseeable (Figure 3d) as it happens with the considerable advancement of corrosion processes shown in Figure 3c.

Meanwhile, the solution in accordance with the patent (Zybura et al., 2012) in which reinforcement corrosion tests are made on cut-out concrete cores containing a fragment of a rebar seems to be the universal one. In this version the counter electrode is applied to the surface of the concrete cover on its entire surface (Figure 2e), so regardless of the environment conductivity and despite the degree of advancement of the corrosion processes the polarization covers the entire surface of the bar fragment - Figure $3 e$ and f. It should certainly be noted that the potential distribution under different conditions is not the same (cross-sections A-A and B-B in Figure 3). Nevertheless, this is of secondary importance for the measurement results.

\section{Conclusions}

Based on the performed potential distribution simulations during DC corrosion polarization studies with the use of the ANSYS Maxwell software it can be concluded that only tests on cores cut from the structure yield reliable results regardless of the reinforcement corrosion rate and the conductivity of the environment. Although the potential distribution in cylindrical specimen may vary, every time the entire surface of the rebar cut out with the concrete is polarized. Tests within the structure, especially without any measures restricting the range of the polarization currents, can lead to gross mistakes in determining the polarization range needed to identify the correct corrosion rate. 
a)

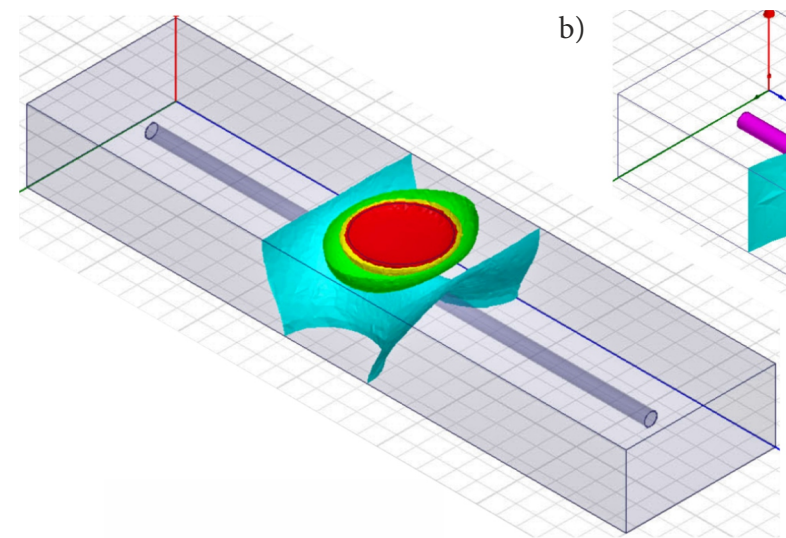

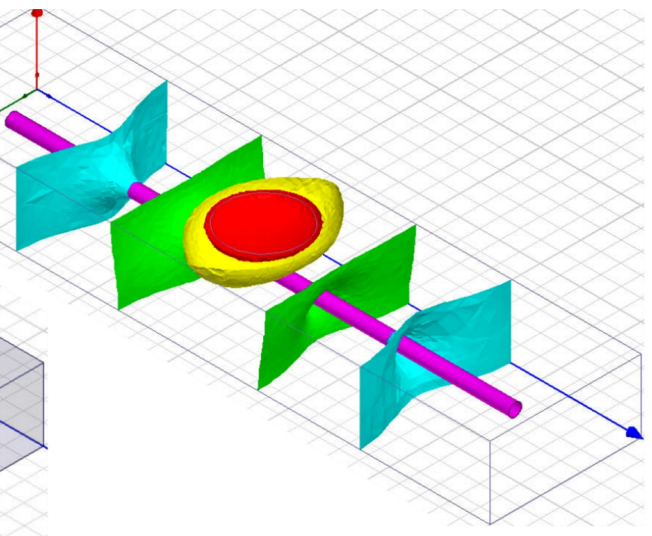

d)

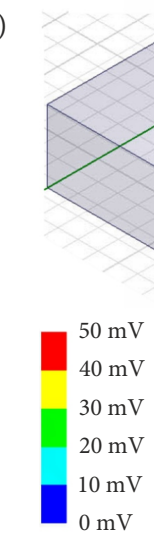

e)

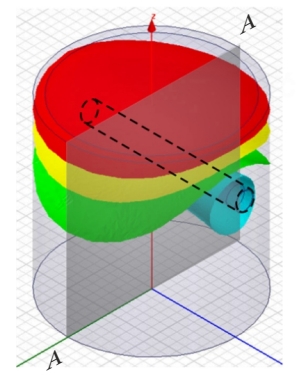

A-A

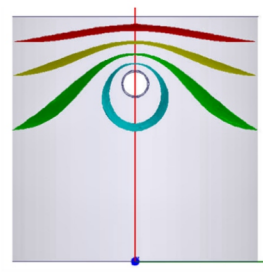

f)

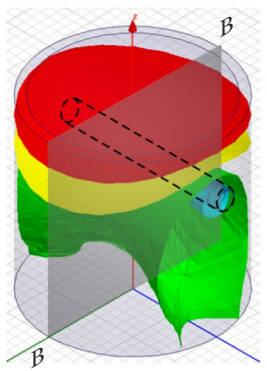

B-B

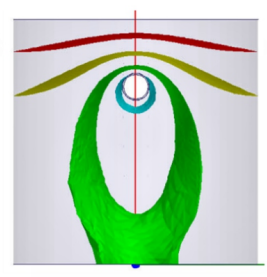

Figure 3. Results of FEM simulation using ANSYS Maxwell - description in the text

\section{References}

Andrade, C., \& Alonso, C. (1996). Corrosion rate monitoring in the laboratory and on-site. Construction \& Building Materials, 10(5), 315-328. https://doi.org/10.1016/0950-0618(95)00044-5

Andrade, C., \& Alonso, C. (2001). On-site measurements of corrosion rate of reinforcements. Construction and Building Materials, 15(2-3), 141-145.

https://doi.org/10.1016/S0950-0618(00)00063-5

Jaśniok, M., \& Jaśniok, T. (2017). Measurements on corrosion rate of reinforcing steel under various environmental conditions, using an insulator to delimit the polarized area. Procedia Engineering, 193, 431-438.

https://doi.org/10.1016/j.proeng.2017.06.234

Zybura, A., Jaśniok, M., \& Jaśniok, T. (2012). Sposób badania szybkości korozji zbrojenia zwłaszcza $w$ konstrukcjach żelbetowych (Patent Rzeczypospolitej PL 224072 B1). 